\title{
From Theory to Practice: Application of Self-Regulation Model for the Management of Fatigue among Cancer Patients Receiving Chemotherapy
}

\author{
Hanem F. Mohamed ${ }^{1,2}$ and Seham A. Abd El-Hay ${ }^{2}$ \\ 1. Assistant Professor, Medical Surgical Nursing, College of Nursing, King Saud Bin Abdulaziz \\ University for Health Sciences, Riyadh, KSA \\ 2. Assistant Professor, Medical Surgical Nursing Department, College of Nursing, Tanta University, \\ Egypt
}

\begin{abstract}
Background: Cancer-related fatigue is a common distressing symptom that is present in most cancer patients at some point during the disease course. According to self-regulation model, inadequate management of fatigue may lead to increased fatigue distress and worsen patients' outcomes. The aim of this study was to evaluate the effect of the application of the self-regulation model on the management of fatigue for cancer patients receiving chemotherapy.

Methods: A quasi-experimental research design was used to collect data from the Clinical Oncology and Nuclear Medicine Department and its relevant outpatient's clinic of Tanta Main University Hospital. A sample of 60 patients was interviewed during their follow-up. Sociodemographic, medical data, cancer fatigue scale, and the selfregulation questionnaire were used to collect data for the study.

Results: Majority were in the age group 41 to 50 and 51 to 60 years old, $50 \%$ were males, $50 \%$ females and $58 \%$ were married. Most of the patients were high school and university graduates. More than half of the patients have had the disease for more than a year and were not smoking. Majority had GIT, pancreatic, kidney and prostatic cancer. Physical, affective, and cognitive fatigue were reduced to the minimum at one month after application of the SRM with significant differences in the fatigue mean score at one month. Self-regulation was obviously improved at one month. Understanding emotions reported a significant association with affective fatigue. In addition, self-regulation and problem-solving reported a significant association with cognitive fatigue.

Conclusion and recommendations: Self-regulation Model applied in this study advises that cognitive and emotional regulation influences health-related behaviours and coping behaviours which influence patients' management and control of their fatigue. Self-regulation model can be incorporated into rehabilitation programs, applied to other types of cancer and chronic illnesses and integrated into nursing curriculum and health education. Further research with a larger sample, qualitative design, and different patients' populations would add more to the nursing body of knowledge.
\end{abstract}

Keywords: Fatigue, Self-Regulation Model, Cancer, Chemotherapy

DOI: $10.7176 / \mathrm{JHMN} / 63-10$

Publication date:June $30^{\text {th }} 2019$

\section{Introduction}

Fatigue is one of the most common symptoms experienced by cancer patients. Cancer-related fatigue (CRF) is multifaceted because it occurs due to the disease itself and as a complication from the treatment. CRF is worse than the feeling of being tired and it impacts patient's activity of daily living and quality of life ${ }^{(1,2)}$. Research indicated that CRF is the most common side effect of cancer treatment and almost all patients are expected to suffer from some degree of fatigue during treatment either with radiotherapy or chemotherapy ${ }^{(3,4)}$.

CRF is defined according to the National Comprehensive Cancer Network as "a persistent, subjective sense of tiredness that interferes with usual functioning ${ }^{(5)}$. The etiology of CRF is complex, involving many contributing elements that include; the direct effect of cancer, side effects associated with anticancer therapies, comorbid medical and psychological conditions, and psychosocial state ${ }^{(6)}$. In advanced cancer stages, the main contributing factors to fatigue are dyspnea, loss of appetite, cachexia, dehydration, and opioid-associated fatigue (7). CRF has subjective and objective symptoms as (physical exhaustion or tiredness), mood changes (depression, sadness, and irritability), motivation alteration (lack of initiative or motivation), cognitive disturbance (impaired 
concentration and memory), and affect social functions (reduced ability to sustain social relationships) ${ }^{(8)}$.

Guidelines for the management of patients with CRF following treatment recommended the use of a cognitivebehavioral theory that aims to influence or change cognitions, emotions, and behaviors of the patients. Cognitivebehavioral theory interventions improve symptoms during the management of the patients ${ }^{(9,10)}$. A common model that has been used in various formats for the development of interventions to enhance coping with CRF is SelfRegulation Model (SRM) that known also as the common-sense model ${ }^{(11)}$. SRM is defined as a system of conscious personal management that involves the process of guiding one's own thoughts, behaviors, and feelings to reach goals. It consists of several stages, and patients must function as the main contributors to their own motivation and behavior ${ }^{(12,13)}$.

SRM for illness and symptoms management is a good representation of the complex symptoms associated disease ${ }^{(\mathbf{1 4})}$. It includes: providing stimuli which represent a problem or symptoms that aggravate patients' reaction either cognitively through understanding it or emotionally through feeling it. According to this stimulation, coping responses of the patients takes place. Coping could be in a form of following a healthy diet, balance between rest and activity or adherence to prescribed medications. After that, the outcomes where patient evaluate the effect of their coping response ${ }^{(\mathbf{1 5}, 16)}$. The main goal of SRMs for CRF is helping patients to appropriately regulate their own cognitive and emotional responses to the objective and subjective experience of fatigue.

Management of CRF is hampered by the lack of patients' knowledge about its etiology and how to control them. Nursing interventions based on self-regulation model help to provide the patients with information that enhances their ability to adjust the health threat, enhance coping abilities and promote symptoms' management abilities. These processes are regulated using individuals' cognitive and emotional representations' The aim of the current study was to evaluate the effectiveness of the application of SRM on the management of fatigue for cancer patients receiving chemotherapy.

\section{Self-Regulation Model}

The SRM (Leventhal, Meyer and Nerenz, 1980) ${ }^{(17)}$ explain the mental process that an individual practice to evaluate the change in his/her body and the coping strategy to control or deal with the health-threatening condition. The health behavior that the individual chose to use to control a health threat is based on 2 interactive components mainly cognitive and emotional. The cognitive component uses the knowledge and available information to interpret and understand the health threat and guide the individual's behavior (Leventhal and Diefenbach, 1991)

(18). The emotional component of SRM represents the individual's affective interpretation of the health-threatening condition and it also affects the individual's interpretation of the situation and associated behavior (Leventhal, Nerenz, \& Straus, 1982) ${ }^{(19)}$. The intervention that is based on SRM for this study provide the cancer patient with the required information to use when they experience fatigue and enhance their ability to manage the severity of the fatigue.

\section{Method}

Research design: A quasi-experimental research design was used for the current study.

Setting: The study was conducted at the Clinical Oncology and Nuclear Medicine Department and its relevant outpatient's clinic of Tanta Main University Hospital, Tanta, Egypt.

Subjects: A convenience sample of 60 patients who are visiting the abovementioned setting to receive their chemotherapy treatment were interviewed. Inclusion criteria included cancer patients at any age, both genders, agree to participate in the study and who are not in a serious condition.

Tools of data collections: Three tools were used to collect data for this study.

Tool (1): Sociodemographic and Medical data of the patients that include Socio-demographic characteristics of patients as age, gender, marital status, occupation, educational level, and residence and patients' clinical data as smoking, duration of the disease and type of cancer.

Tool (2): Cancer Fatigue Scale, CFS: The Cancer Fatigue Scale (Okuyama et al., 2000) ${ }^{(20)}$ was utilized to assess fatigue among cancer patients in this study. The scale is 15 items 5-points Likert scales with 5(very much), 4 (considerably), 3 (somewhat), 2 (a little) and 1(no). The scale has 3 subscales that include physical, affective and cognitive fatigue.

\section{Tool (3): Self-Regulation Questionnaire:}

A modified version of the Self-Regulation Questionnaire (SRQ) was first developed by Kanfer (1970) ${ }^{(21)}$ then 
modified by Brown (1998) ${ }^{(22)}$ and Brown et. al. (1999) ${ }^{(23) . ~ I t ~ i s ~ a ~} 20$-item self-report measuring of the ability to regulate behavior to achieve one's goals. Participants indicate the extent to which they agree with each item using a 5-point Likert scale: 1 (Strongly Disagree), 2 (Disagree), 3 (Neutral), 4 (Agree), and 5 (Strongly Agree).

\section{Ethical consideration:}

Official permission was obtained from the Head of the Clinical Oncology and Nuclear Medicine Department and its relevant outpatient's clinic of Tanta Main University Hospital. Informed consent was taken from every patient after clarifying the procedures and the purpose to participate in the study. Patients were informed about the confidentiality of data, their voluntary participation and withdrawal at any time without any consequences. Confidentiality was followed using codes and numbers instead of names.

\section{Procedure of data collection:}

After preparing the tools of the study, the researchers approached the eligible subjects during their follow up for receiving treatment and explained the study purposes. Those who agree to participate were interviewed by the researchers after arranging them in groups to apply the SRM. The groups don't include a fixed number of patients since patients come to receive their chemotherapy session based on a schedule and not all of them started treatment at the same time. An effort was made to include patients who are similar in the number of treatment sessions in one group. The implementation of the self-regulation model was carried out through four phases (assessment, planning, implementation, and monitoring).

Assessment phase: The patients were assessed in the $1^{\text {st }}$ week before the application of the self-regulation model to collect baseline data using tool 1 and 2. Due to the nature of the illness and to avoid adding burden on the patients, they were interviewed by the researchers before the start of the treatment session. Baseline data were collected and planning for the implementation session was done.

Planning phase: In this phase, the researchers utilized SRM to design the needed information to manage CRF and contents were written in simple Arabic language to guide the patients based on a review of literature. Different methods were used as video, group discussion, and power point presentations along with the written materials. The self-regulatory model includes sets of goals, outlines strategies and creates a schedule for the task. The instructions included general and specific objective for the self-regulatory model, information regarding fatigue signs and symptoms, how to manage and control the symptoms, how to improve activities of daily living, and balance between rest and activities, keep a regular sleep schedule, keep regular meals, drink plenty of fluids, and practice an activity that patients like for a few minutes about 2 to 3 times a week.

Implementation phase: application of SRM was implemented by the researchers in 3 sessions as follow: First session focused on increasing patients' awareness about fatigue through discussing causes, signs, and symptoms, needed laboratory tests, dietary plan and activity and rest. Second session: focused on enhancing cognitive representation of patients for their problem through encouraging them to talks to his/her doctor, friend or family member, write down their complains, recalls a friend's experience with cancer who had similar sense of fatigue, thinks about a famous character who experienced cancer related fatigue, and try to remember what they learned about cancer-related fatigue in their life. The session also focused on improving the emotional representation of patients toward his problem through teaching the patients to express their feelings, express worry about his/her health and life, express anxiety about how much his life will change, show fear about what will happen and how life will change. The third session: focused on helping patients to make decisions about the plan of care and how to modify lifestyle to control their fatigue. This done through providing healthy choices as healthy diet, balance between rest and activity, keep a regular sleep schedule, taken a short walk each day, visit or invite friends or relatives to visit, practice hobbies or volunteer for humanitarian work. In this session, skills and techniques to enhance self-regulation were identified such as regulation of negative emotions and manage emotion regulation, carry out plans and monitor performance, build cognitive appraisal to assess coping and change strategy as needed.

Evaluation phase: In this phase, tool 2 and 3 were used to collect data on fatigue and self-regulation after 2 weeks and after one month from the implementation of the program.

Implementation of the self-regulation model was performed in a well-controlled environment with good ventilation, no noise and maintained privacy as possible. Sessions were provided 3 days a week for groups ranging from 6 to 10 patients based on their treatment schedule. Each session lasted from 1 to 1 and half hour and sessions continued until reached a total of 60 patients. In the first meeting, sociodemographic and clinical data and data on fatigue were collected. Two weeks and one month later, data on fatigue and self-regulation were collected to evaluate how cancer patients use self-regulation model to manage their fatigue. 


\section{Data analysis:}

Data were analyzed using Statistical Package for Social Sciences (SPSS) version 21. Descriptive statistics, paired sample t-test, and correlation analyses were used to describe the study variables.

\section{Results}

Descriptive statistics of the demographic characteristics of the sample showed that $48.3 \%$ were in the age group 41 to 50 years old, and 35\% were in the age group 51 to 60 years old. Fifty percent were males and $50 \%$ were females. $58 \%$ were married, $18 \%$ were widowed and $15 \%$ were singles. Regarding education $40 \%$ were university graduates, $38 \%$ had high school and $20 \%$ reported having primary school education. Regarding work, $43 \%$ were having professional work while $40 \%$ were not working. A majority $(60 \%)$ were residents of urban areas and $54 \%$ were not smokers. Concerning the duration of the disease, $52 \%$ had the disease for more than one year, $28 \%$ for less than one year and $20 \%$ for a year. $33 \%$ had GIT and pancreatic cancer, $22 \%$ reported having kidney and prostatic cancer, $15 \%$ had hematology and other types of cancer and $11.9 \%$ had lung cancer. Demographic and clinical data of the patients are presented in table 1.

Table 1: Demographic and clinical data of the study sample.

\begin{tabular}{|c|c|c|}
\hline & $\begin{array}{l}\# \\
N=60\end{array}$ & $\%$ \\
\hline \multicolumn{3}{|l|}{ Age } \\
\hline 20-30 years old & 0 & 0 \\
\hline 31 to 40 years old & 7 & 11.7 \\
\hline 41 to 50 years old & 29 & 48.3 \\
\hline 51 to 60 years old & 21 & 35 \\
\hline$>61$ & 3 & 5 \\
\hline \multicolumn{3}{|l|}{ Gender } \\
\hline Male & 30 & 50 \\
\hline Female & 30 & 50 \\
\hline \multicolumn{3}{|l|}{ Marital Status } \\
\hline Married & 35 & 58.3 \\
\hline Single & 9 & 15 \\
\hline Divorced & 5 & 8.3 \\
\hline Widow & 11 & 18.3 \\
\hline \multicolumn{3}{|l|}{ Education } \\
\hline Illiterate & 1 & 1.7 \\
\hline Primary school & 12 & 20 \\
\hline High school & 23 & 38.3 \\
\hline University & 24 & 40 \\
\hline \multicolumn{3}{|l|}{ Occupation } \\
\hline Professional work & 26 & 43.3 \\
\hline Blue collars & 10 & 16.7 \\
\hline Not working & 24 & 40 \\
\hline \multicolumn{3}{|l|}{ Residence } \\
\hline Rural & 24 & 40 \\
\hline Urban & 36 & 60 \\
\hline
\end{tabular}




\begin{tabular}{|l|l|l|}
\hline Smoking & 35 & 45.5 \\
Yes & 42 & 54.5 \\
\hline Do & & \\
Less than a year & 17 & $28 \%$ \\
One year & 12 & $20 \%$ \\
More than one year & 31 & $52 \%$ \\
\hline Type of cancer & & \\
GIT \& pancreas & 20 & 33.3 \\
Lung & 7 & 11.6 \\
Head \& neck & 2 & 3.3 \\
Kidney \& prostate & 13 & 22 \\
Hematology & 9 & 15 \\
Other types & 9 & 15 \\
\hline
\end{tabular}

\section{Fatigue}

Fatigue was measured with a 15-item 5-points Liker scale. The 15-items are divided into 3-subscales; physical, affective and cognitive fatigue. Results pre-implementing the SRM showed that regarding physical fatigue, one quarter reported having a little, considerably and very much fatigue. Two weeks after application of SRM, physical fatigue was reported as no among $51.7 \%$, and a little among $48.3 \%$ while after one month $76.7 \%$ reported no fatigue and $23.3 \%$ reported a little fatigue.

Affective fatigue reported improvement with time since $28.3 \%$ reported a little, $25 \%$ reported somewhat and $16,7 \%$ reported either no fatigue or very much fatigue pre-implementation of SRM, while 2 weeks after $85 \%$ reported a little and $15 \%$ reported no fatigue. After one month, $81.7 \%$ reported no fatigue and $16.7 \%$ reported a little fatigue.

As for cognitive fatigue, pre-implementation of SRM, results showed that $33.3 \%$ reported a little fatigue and $25 \%$ somewhat and very much fatigue. Two weeks after, $76.7 \%$ reported a little and $23.3 \%$ reported no cognitive fatigue while after one month $51.7 \%$ reported having no fatigue and $45 \%$ reported a little cognitive fatigue. Results of fatigue pre and post the application of SRM are presented in table 2.

Table 2: Percentage of fatigue subscales pre and post application of the SRM

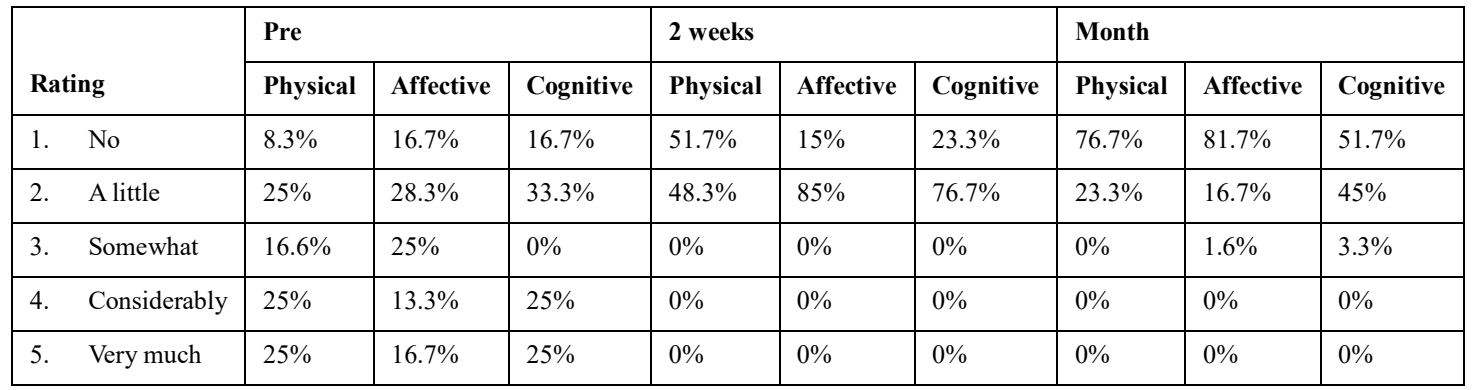

As shown in table 3, paired sample t-test was conducted to examine if there is a significant change in the mean score of fatigue subscales pre-application of the model, 2 weeks and one month later. Results showed that there were statistically significance differences in the 3 fatigue subscales mean scores only one month after application of the model as follow: physical fatigue $(\mathrm{t}=11.75, \mathrm{p}=.02)$, affective fatigue $(\mathrm{t}=9.77, \mathrm{p}=.000)$ and cognitive fatigue $(\mathrm{t}=10.32, \mathrm{p}=.01)$. 
Table 3: Differences in the mean score of fatigue subscales pre, 2 weeks and one month after application of SRM

\begin{tabular}{|l|l|l|l|l|l|l|}
\hline Fatigue subscales & & Mean & SD & df & t & P-value \\
\hline \multirow{5}{*}{ Physical fatigue } & Pre & 2.01 & .50 & 59 & 8.35 & .23 \\
\cline { 2 - 4 } & 2 weeks & 2.48 & .59 & & 10.11 & .25 \\
\cline { 2 - 4 } \cline { 2 - 3 } & One month & 1.52 & .48 & & 11.75 & $\mathbf{. 0 2}$ \\
\hline Affective fatigue & Pre & 1.95 & .36 & 59 & 11.21 & .38 \\
\cline { 2 - 4 } & 2 weeks & 1.85 & .44 & & 8.91 & .51 \\
\cline { 2 - 4 } & One month & 1.20 & .51 & & 9.77 & $\mathbf{. 0 0 0}$ \\
\hline Cognitive fatigue & Pre & 1.91 & .42 & 59 & 8.22 & .73 \\
\cline { 2 - 4 } & 2 weeks & 1.76 & .43 & & 11.21 & .46 \\
\cline { 2 - 4 } & One month & 1.23 & .51 & & 10.32 & $\mathbf{. 0 1}$ \\
\hline
\end{tabular}

\section{Self-regulation}

Self-regulation was measured twice after application of SRM, first time after 2 weeks and the second time after one month. Results 2 weeks after application of the model showed that: regarding understanding emotions subscale, $41.6 \%$ were always and $21.6 \%$ often, $25 \%$ sometimes and $18.3 \%$ were never able to understand emotions. After one month, $68.3 \%$ reported that they were always and $18.3 \%$ often were able to understand emotions.

Regarding self-regulation subscale 2 weeks after application of the model, $28.3 \%$ reported always, $41.6 \%$ reported often and $20 \%$ sometimes. One month after application of the model, self-regulation abilities reported as always among $50 \%$, as often among $25 \%$ and sometimes among $15 \%$ of the patients.

Regarding flexibility subscale after 2 weeks, $33.3 \%$ reported that they were always, $31.6 \%$ were often and $35 \%$ were sometimes flexible. After one month, $41.6 \%$ reported that they were always, $25 \%$ were often and $16.6 \%$ were sometimes flexible.

Problem solving subscale after 2 weeks reported as always among $26.6 \%$, as often among $40 \%$, sometimes among $20 \%$ and never among $13.3 \%$ of the patients while after one-month, problem-solving abilities were reported as always among $30 \%$, as often among $48.3 \%$, and sometimes among $16.6 \%$ of the patients. Selfregulation results are showed in table 4.

Table 4: Number and Percentage of patients' self-regulation 2 weeks and one month after application of the SRM model

\begin{tabular}{|c|c|c|c|c|c|}
\hline & \multirow{2}{*}{$\begin{array}{l}\text { Time of } \\
\text { measurement }\end{array}$} & $\begin{array}{l}\text { Understanding } \\
\text { emotions }\end{array}$ & Self regulation & Flexibility & $\begin{array}{l}\text { Problem } \\
\text { Solving }\end{array}$ \\
\hline & & \# (\%) & \# (\%) & \# (\%) & \# (\%) \\
\hline \multirow[t]{2}{*}{ Always } & 2 weeks & $21(41.6)$ & $17(28.3)$ & $20(33.3)$ & $16(26.6)$ \\
\hline & 1 month & $41(68.3)$ & $30(50)$ & $25(41.6)$ & $18(30)$ \\
\hline \multirow[t]{2}{*}{ Often } & 2 weeks & $13(21.6)$ & $25(41.6)$ & $19(31.6)$ & $24(40)$ \\
\hline & 1 month & $11(18.3)$ & $15(25)$ & $15(25)$ & $29(48.3)$ \\
\hline \multirow[t]{2}{*}{ Sometimes } & 2 weeks & $15(25)$ & $12(20)$ & $21(35)$ & $12(20)$ \\
\hline & 1 month & $7(11.6)$ & $9(15)$ & $10(16.6)$ & $10(16.6)$ \\
\hline \multirow[t]{2}{*}{ Never } & 2 weeks & $11(18.3)$ & $5(8.3)$ & $0(0)$ & $8(13.3)$ \\
\hline & 1 month & $1(1.6)$ & $6(10)$ & $0(0)$ & $3(5)$ \\
\hline
\end{tabular}

To test if there is a significant change in the mean score of self-regulation 2 weeks and one month after application of the SRM, as shown in table 5, results of paired sample t-test showed that there were statistically significant differences in the mean score of understanding emotions $(\mathrm{t}=10.32, \mathrm{p}=.001)$ and self-regulation $(\mathrm{t}=$ $8.92, \mathrm{p}=.002)$ at one month. There were no significant differences in the mean score of inflexibility and problem- 
solving.

Table 5: Differences in the mean score of self-regulation at 2 weeks and one month after application of SRM

\begin{tabular}{|c|c|c|c|c|c|c|}
\hline Self-Regulation subscales & & Mean & SD & df & $\mathbf{T}$ & P-value \\
\hline \multirow[t]{2}{*}{ Understanding emotions } & 2 weeks & 2.23 & .43 & \multirow[t]{8}{*}{59} & 9.21 & .61 \\
\hline & One month & 1.44 & .39 & & 10.32 & .001 \\
\hline \multirow[t]{2}{*}{ Self-regulation } & 2 weeks & 1.44 & .39 & & 11.12 & .52 \\
\hline & One month & 2.32 & .36 & & 8.92 & .002 \\
\hline \multirow[t]{2}{*}{ Flexibility } & 2 weeks & 2.54 & .63 & & 9.11 & .43 \\
\hline & One month & 2.22 & .45 & & 10.41 & .32 \\
\hline \multirow[t]{2}{*}{ Problem solving } & 2 weeks & 2.34 & .42 & & 11.23 & .31 \\
\hline & One month & 2.11 & .42 & & 9.42 & .71 \\
\hline
\end{tabular}

Correlation analysis was conducted to test if there is an association between self-regulation subscales (understanding emotions, self-regulation, flexibility, and problem-solving) and fatigue subscales (physical, affective and cognitive) after 2 weeks and one month. Results indicated that understanding emotions significantly correlated with affective fatigue $\left(\mathrm{r}=-.41^{* *}, \mathrm{p}=.01\right)$ after one month meaning that those who were able to understand and regulate their emotions were less likely to have affective fatigue.

Self-regulation reported significance correlation with cognitive fatigue after one month $\left(\mathrm{r}=-.39^{* *}, \mathrm{p}=.001\right)$, patients who reported better self- regulation abilities reported a lower level of cognitive fatigue. In addition, problem-solving showed significant correlation with cognitive fatigue after one month $\left(\mathrm{r}=-.31^{* *}, \mathrm{p}=.03\right)$ indicating that with better problem-solving abilities, patients were less likely to feel cognitive fatigue. Correlation analysis results are presented in table 6.

Table 6: Correlations between self-regulation and fatigue among the studied sample one month after application of the SRM

\begin{tabular}{|l|l|l|l|}
\hline Self-regulation subscales & \multicolumn{2}{|l|}{ Fatigue subscales } \\
\cline { 2 - 4 } & Physical fatigue & Affective fatigue & Cognitive fatigue \\
\hline Understanding emotions & $\mathrm{r}=.01$ & $\mathrm{r}=-.41^{* *}$ & $\mathrm{r}=.01$ \\
& $\mathrm{p}=.21$ & $\mathrm{p}=.01$ & $\mathrm{p}=.33$ \\
\hline Self-regulation & $\mathrm{r}=.021$ & $\mathrm{r}=.02$ & $\mathrm{r}=-.39 * *$ \\
& $\mathrm{p}=.31$ & $\mathrm{p}=.81$ & $\mathrm{p}=.001$ \\
\hline Flexibility & $\mathrm{r}=.03$ & $\mathrm{r}=.001$ & $\mathrm{r}=.01$ \\
& $\mathrm{p}=41$ & $\mathrm{p}=.63$ & $\mathrm{p}=.72$ \\
\hline Problem-solving & $\mathrm{r}=.011$ & $\mathrm{r}=.011$ & $\mathrm{r}=-.31^{* *}$ \\
& $\mathrm{p}=.25$ & $\mathrm{p}=.14$ & $\mathrm{p}=.03$ \\
\hline
\end{tabular}

To test if there is association between demographic variables (age, gender, marital status, education, occupation, residence) and medical data (type of cancer, duration of the disease and smoking) and self-regulation subscales (understanding emotions, self-regulation, flexibility and problem solving), results of Chi-square test as shown in table 7 reported that marital status reported significant association with self-regulation $(\mathrm{Chi}=1.34, \mathrm{p}=.002)$ and problem-solving $(\mathrm{Chi}=1.91, \mathrm{p}=.01$ ) indicating that married patients have better ability of self-regulation and problem-solving.

Education reported significance association with understanding emotions $(\mathrm{Chi}=2.01, \mathrm{p}=.02)$ meaning that well educated patients were more likely to understand their emotions. 
Table 7: Association between demographic and medical variables and self-regulation subscales

\begin{tabular}{|l|l|l|l|l|}
\hline \multirow{2}{*}{$\begin{array}{l}\text { Demographic and } \\
\text { medical data }\end{array}$} & \multicolumn{3}{|l|}{ Self-Regulation subscales } \\
\cline { 2 - 5 } & $\begin{array}{l}\text { Understanding } \\
\text { emotions }\end{array}$ & Self-Regulation & Flexibility & $\begin{array}{l}\text { Problem- } \\
\text { Solving }\end{array}$ \\
\hline Age & $\begin{array}{l}\text { Chi }=1.23 \\
\mathrm{p}=.21\end{array}$ & $\begin{array}{l}\text { Chi }=11.25 \\
\mathrm{p}=.11\end{array}$ & $\begin{array}{l}\mathrm{Chi}=1.92 \\
\mathrm{p}=.33\end{array}$ & $\begin{array}{l}\text { Chi }=2.21 \\
\mathrm{P}=.34\end{array}$ \\
\hline gender & $\mathrm{Chi}=2.51$ & $\mathrm{Chi}=.172$ & $\mathrm{Chi}=2.65$ & $\mathrm{Chi}=2.39$ \\
& $\mathrm{p}=.31$ & $\mathrm{p}=.81$ & $\mathrm{p}=.37$ & $\mathrm{P}=.71$ \\
\hline Marital status & $\mathrm{Chi}=2.45$ & $\mathbf{C h i}=\mathbf{1 . 3 4}$ & $\mathrm{Chi}=2.61$ & $\mathbf{C h i}=\mathbf{1 . 9 1}$ \\
& $\mathrm{p}=41$ & $\mathbf{p}=\mathbf{. 0 0 2}$ & $\mathrm{p}=.72$ & $\mathbf{p}=. \mathbf{0 1}$ \\
\hline Education & $\mathrm{Chi}=2.01$ & $\mathbf{C h i}=\mathbf{1 . 0 1}$ & $\mathrm{Chi}=2.71$ & $\mathrm{Chi}=1.37$ \\
& $\mathrm{p}=.14$ & $\mathbf{p}=\mathbf{. 0 2}$ & $\mathrm{p}=.73$ & $\mathrm{p}=.32$ \\
\hline Occupation & $\mathrm{Chi}=2.39$ & $\mathrm{Chi}=2.11$ & $\mathrm{Chi}=1.91$ & $\mathrm{Chi}=2.00$ \\
& $\mathrm{p}=.21$ & $\mathrm{p}=.35$ & $\mathrm{p}=.51$ & $\mathrm{p}=.62$ \\
\hline Residence & $\mathrm{Chi}=1.54$ & $\mathrm{Chi}=1.76$ & $\mathrm{Chi}=1.75$ & Chi $=1.84$ \\
& $\mathrm{p}=.43$ & $\mathrm{p}=.52$ & $\mathrm{p}=.23$ & $\mathrm{p}=.11$ \\
\hline $\begin{array}{l}\text { Duration } \\
\text { disease }\end{array}$ & $\mathrm{Chi}=2.65$ & $\mathrm{Chi}=2.11$ & $\mathrm{Chi}=1.51$ & Chi $=2.32$ \\
\hline Type of cancer & $\mathrm{p}=.10$ & $\mathrm{p}=.21$ & $\mathrm{p}=.12$ & $\mathrm{p}=.16$ \\
\hline & $\mathrm{Chi}=2.65$ & $\mathrm{Chi}=2.15$ & $\mathrm{Chi}=2.51$ & Chi $=1.65$ \\
& $\mathrm{p}=.10$ & $\mathrm{p}=.19$ & $\mathrm{p}=.15$ & $\mathrm{p}=.17$ \\
\hline
\end{tabular}

\section{Discussion}

Results from this study showed that theory-based intervention using the SRM directly enhanced affective and cognitive fatigue among cancer patients receiving chemotherapy. Earlier studies also showed that autonomic and self-regulation intervention have an independent impact on global and cognitive fatigue, self-regulation, and reduced anxiety and depression among breast cancer patients ${ }^{(24)}$. Educational programs on self-care regulation for patients with colorectal cancer who are receiving chemotherapy was also effective in reducing the intensity of symptoms such as nausea and vomiting ${ }^{(25)}$. In addition, qualitative research concluded that when SRM was used, participants were able to understand their fatigue and appraise coping which helped them to have better control and management ${ }^{(26)}$. Similar results were also reported for different kinds of cancers. Psychoeducational intervention with SRM was effective in improving ovarian cancer patient's symptoms representation ${ }^{(27)}$. SRM reported successful effect in changing illness representations, improving quality of life, and reducing psychological distress for CABG patients and head and neck cancer patients ${ }^{(28,29)}$. SRM predicted a better understanding of how people perceive disease and was used to develop successful interventions for smoking cessation for cancer patients (30).

This study showed a significant association between understanding emotions and affective fatigue. The ability to regulate and appraise emotions were effective in reducing affective fatigue. Although the causal effect of emotion regulation on physical and mental health is not clear, research has demonstrated the impact of emotion regulation on health. This effect needs more study especially for cancer patients to be able to develop intervention aiming to reduce maladaptive emotion regulation to improve patient's outcomes. Previous research also reported positive consideration of emotion regulation on health ${ }^{(31,32)}$.

Self-regulation and problem- solving predicted cognitive fatigue in the current study. It is assumed that positive emotions positively affect cognition and behavior especially with chronic illness and play a protective role in stress reduction through enhancing individuals' ability to cope with and control health issues. Applying the self-regulation model in this study enhanced cognitive and emotion regulation strategies which in turn reduced affective and cognitive fatigue and this was consistent with the previous study ${ }^{(33)}$. 
Although results from this study did not report a direct association between self-regulation and physical fatigue, descriptive statistics reported improvement of physical fatigue over time among patients. The relationship between emotions and health is complex and there is always a link between them. As postulated by SEM, emotion regulation enables individuals to appraise and evaluate life-threatening situations and in turn moderate physical responses to stressors. Such an effect could occur directly or indirectly based on the situation and the selfregulation abilities of the individual.

Further, the current study showed that marital status reported significance association with self-regulation and problem solving. There were no available data to compare our results with, however, married people can receive different types of support from spouses and children. These supports provide emotional intimacy and family wellbeing which in turn improve the individuals' problem-solving and self-regulation abilities. Research has proven that married people who have good relationship are more emotionally stable, supported, and able to cope with challenging stressful experiences ${ }^{(34)}$.

Education on the other hand reported significance association with self-regulation. Well educated people have the ability for self-regulation, they can set attainable goals, take appropriate actions to achieve these goals and able to manage their emotional processes to cope with painful situations ${ }^{(35,36)}$.

\section{Conclusion and recommendations:}

SRM applied in this study advises that cognitive and emotions regulation influences health-related behaviors and coping behaviors which impacts patients' management and control of their fatigue. For this reason, it would be beneficial for cancer patients who suffer from fatigue to utilize such a model. SRM can be incorporated into rehabilitation programs and applied to other types of cancer and chronic illnesses. SRM could also be a useful framework for healthcare professionals to apply in assessments of cancer survivors to effectively tailor care. Integrating SRM and other models into the nursing curriculum and health education is important. Further research with a larger sample, qualitative design, and different patients' populations would add more to the nursing body of knowledge.

Limitations: Although the current study had patients from different residential areas and utilized a structured interview, it is limited to a relatively small sample size. Including patients with lower educational level would be better because they need to enhance their abilities to manage their fatigue. Also, including a specific type of cancer would have portrayed the effect of applying the SRM for a specific type of cancer, then apply to other types.

\section{Reference}

1. Tazi, E. and Errihani, H. (2011). Evaluation and Management of Fatigue in Oncology: A Multidimensional Approach, Indian Journal of Palliative Care, 17(2), 92-97.

2. Stone, P., Richardson, A., Smith, R., Kerr, D. and Kearney, N. (2000). Cancer-related fatigue: inevitable, unimportant and untreatable? Results of a multi-center patient survey. Cancer Fatigue Forum. Annals of Oncology, 11(8):971-975.

3. Wang, X., Zhao, F., and Fischm M. (2014). Prevalence and characteristics of moderate to severe fatigue: a multicenter study in cancer patients and survivors. Cancer, 120(3), 425-432.

4. Savina, S. and Zaydiner, B. (2019). Cancer-Related Fatigue: Some Clinical Aspects, Asia Pacific Journal of Oncology Nursing, 6(1), 7-9.

5. Mock, V., Atkinson, A., Barsevick, A., Cella, D., Cimprich, B., and Cleeland, C. (2000). NCCN practice guidelines for cancer-related fatigue. Oncology (Huntingt), 14, 151-161.

6. Berger, A., Abernethy, A., Atkinson, A., Barsewick, A., Breitbart, W., and Cella, D. (2009). Cancerrelated Fatigue. Practice Guidelines in Oncology Version, (1). Retrieved from http:// www. nccn.org/professionals/physician gls/PDF/fatigue, pdf.

7. Okuyama, T., Tanaka, K., and Akechi, T. (2001). Fatigue in ambulatory patients with advanced lung cancer: prevalence, correlated factors, and screening. Journal of Pain Symptom Management, 22, 554564.

8. Goedendorp, M., Gielissen, M., Verhagen, C., and Bleijenberg, G. (2009). Psychological interventions for reducing fatigue during cancer treatment in adults. Cochrane Database Systematic Review, 21 (1), 6953. 
9. Nathan, D., Roy, B., Matthew, G., and Jon, M. (2008). Depletion Makes the Heart Grow Less Helpful: Helping as a Function of Self-Regulatory Energy and Genetic Relatedness. Personality and Social Psychology Bulletin, 34 (12), 1653-1662.

10. Roy, B. Kathleen, V. and Dianne, T. (2007). "The Strength Model of Self-Control". Current Directions in Psychological Science, 16 (6), 351-355.

11. Baumeister, R. and Vohs, K. (2007). Self-regulation, ego depletion, and motivation. Social and Personality Psychology Compass, 1, 115-128.

12. Bell, A. (2016). What is self-regulation and why is it so important? Good Therapy Blog. 2016. Retrieved from https://www.goodtherapy.org/blog/what-is-self-regulation-why-is-it-so-important-0928165.

13. Connelly, M. (2012). Self-regulation. Change Management Coach. Retrieved from https://www.changemanagement-coach.com/self-regulation.html.

14. Reuille, K. (2002). Using self-regulation theory to develop an intervention for cancer-related fatigue, clinical nurse specialist, 2002, Lippincott Williams \& Wilkins, inc., 314.

15. Johnson, J. (1997). Self-Regulation Theory: Applying Theory to Your Practice. Pittsburgh, Pa: Oncology Nursing Press; 1997.

16. Fowler, C., Kirschner, M., Van Kuiken, D. and Baas, L. (2007). Promoting self-care through symptom management: A theory-based approach for nurse practitioners. Journal of the American Academy of Nurse Practitioners, 19(5), 221-227.

17. Leventhal, H., Meyer, D., \& Nerenz, D. (1980). The common-sense representation 2 pp. 7-30) Illness danger, In S. Rachman (ed.), Contribution to medical psychology, (Vol 30) Oxford, England: Pergamon Press.

18. Leventhal, H. \& Deifenbach, M. (1991). 'The active side of illness cognition,' in J.A Skelton and R.T. Croyle (eds) Mental Representation in Health and Illness. New York: Springer-Verag, pp. 247-272.

19. Leventhal, H., Nerenz, D.R., \& Straus, A. (1982). Self-regulation and the mechanisms of symptoms appraisal. In D Mechanic, (ed.), Symptoms, illness behavior, and help-seeking (pp. 55-86) New York: Prodist.

20. Okuyama, T., Akechi, T., Kugaya, A., Okamura, H., Shima, Y. et al. (2000). Development and Validation of the Cancer Fatigue Scale. Journal of Pain and Symptoms Management, 19(1), 5-14.

21. Kanfer, F. H. (1970a). Self-monitoring: Methodological limitations and clinical application Journal of Consulting and Clinical Psychology, 35, 148-152.

22. Brown, J. M. (1998). Self-regulation and the addictive behaviors. In W. R. Miller \& N. Heather (Eds.), Treating addictive behaviors (2nd ed., pp. 61-74). New York: Plenum Press.

23. Brown, J., Miller, W., and Lawendowski, L. (1999). The Self-Regulation Questionnaire, Innovations in clinical practice: A source book, 1999; 17: 281-289). Sarasota, FL: Professional Resource Press.

24. Kroz, M., Reif, M., Bartsch, C and Heckmann, C. (2014). Impact of autonomic and self-regulation on cancer-related fatigue and distress in breast cancer patients - a prospective observational study. Journal of Cancer Survivorship, 8 (2), 319-328.

25. Karimi, S., Makhsosi, B.R., Seyedi-Andi, S.J., Behzadi, M., Moghofeh, Y., Mohammad, K., et al. (2017). Surveying the effect of a self-care education program on the severity of nausea and emesis in colorectal cancer patients under chemotherapy. Journal of Multidisciplinary Healthcare, 10:301-307.

26. Corbett, T., Groarke, A., Walsh, J., and McGuire, B. (2016). Cancer-related fatigue in post-treatment cancer survivors: application of the common-sense model of illness representations. BMC Cancer, 16:919-936.

27. Donovan, H.S., Ward, S., Sherwood, P., Serlin, R.C. (2008). Evaluation of the symptom representation questionnaire (SRQ) for assessing cancer-related symptoms. Journal of Pain and Symptom Management, $35,242-257$.

28. Llewellyn, C.D., McGurk, M., Weinman, J. (2007). Illness and treatment beliefs in head and neck cancer: Is Leventhal's common-sense model a useful framework for determining changes in outcomes over time? Journal of Psychosomatic Research, 63, 7-26.

29. Scharloo, M., Baatenburg, R.J., Langeveld, T.P. et al. (2005). Quality of life and illness perceptions in 
patients with recently diagnosed head and neck cancer. Head Neck, 27, 857-863.

30. Garces, Y.I., Yang, P., Parkinson, J., et al. (2004). The relationship between cigarette smoking and quality of life after lung cancer diagnosis. Chest, 126, 1733-1741.

31. Song, Y., Lu, H., Hu, S., Xu, M., Li, X., \& Liu, J. (2015). Regulating emotion to improve physical health through the amygdala. Social Cognitive and Affective Neuroscience, 10, 523-530.

32. Heck, G. L., \& den Oudsten, B. L. (2008). Emotional Intelligence: Relationships to Stress, Health, and Well-being. In A. Vingerhoets, I. Nyklicek \& J. Denollet (Eds.), Emotion regulation: Conceptual and clinical issues. New York, NY: Springer.

33. Reuille, K. (2002). Using Self-regulation Theory to Develop an Intervention for Cancer-related Fatigue. Clinical Nurse Specialist, 16 (6), 312-319.

34. Amato, P. R., Booth, A., Johnson, D. R., \& Rogers, S. J. (2007). Alone together: How marriage in America is changing. Cam-bridge: Harvard University Press.

35. Miller DC, Byrnes JP. (2001). Adolescents' decision making in social situations: A self-regulation perspective. Journal of Applied Developmental Psychology, 22:237-56.

36. Van Ewijk CD. (2011). Assessing students' acquisition of self-regulated learning skills using metaanalysis. In: Zimmerman BJ, Schunk DH, editors. Handbook of Self-Regulation of Learning and Performance. Milton Park: Taylor \& Francis; 2011. pp. 376-90 